\title{
LOS FENOLES DEL POLEN DEL GÉNERO ZEA
}

\author{
Norma Almaraz-Abarca ${ }^{1,5}$, Diana María Rivera-Rodríguez ${ }^{1}$, David Arráez- \\ Román ${ }^{2,3}$, Antonio Segura-Carretero ${ }^{2,3}$, José de Jesús SÁnchez-González ${ }^{4}$, \\ Amanda Delgado-Alvarado ${ }^{1}$, José Antonio Ávila-Reyes ${ }^{1}$
}

${ }^{1}$ Instituto Politécnico Nacional, Centro Interdisciplinario de Investigación para el Desarrollo Integral Regional, Unidad Durango, Sigma 119, Fraccionamiento 20 de Noviembre II, 34220 Durango, Durango, México.

${ }^{2}$ Universidad de Granada, Facultad de Ciencias, Departamento de Química Analítica, Avenida Fuente nueva s/n, 18071 Granada, España.

${ }^{3}$ Centro de Investigación y Desarrollo del Alimento Funcional, Parque Tecnológico de Ciencias de la Salud, Avenida del Conocimiento 3, 18100 Granada, España. ${ }^{4}$ Universidad de Guadalajara, Centro Universitario de Ciencias Biológicas y Agropecuarias, km 15.5 Carretera a Nogales, 45101 Zapopan, Jalisco, México.

${ }^{5}$ Autor para la correspondencia: nalmaraz@ip.mx; noralab@yahoo.com

\section{RESUMEN}

Se analizó la variabilidad de la composición fenólica del polen de 32 poblaciones de Zea mays subsp. mexicana, Zea mays subsp. parviglumis, Zea mays subsp. mays, Zea diploperennis, Zea perennis y Zea luxurians de México y Guatemala. Los perfiles se obtuvieron por cromatografía líquida de alta presión con detector de arreglo de diodos (HPLC-DAD) y cromatografía líquida de ultra resolución acoplada a espectrómetro de masas de tiempo de vuelo (UPLC-TOF-MS). Se encontró un total de 23 compuestos fenólicos (cuatro ácidos fenólicos, 16 flavonoles y tres dihidroflavonoides). Los derivados glicósidos de quercetina (siete derivados, además de la quercetina aglicona misma) fueron las substancias predominantes en todos los analisis realizados. El compuesto principal, el más abundante y presente en la totalidad de las muestras, incluido el maíz, se identificó como quercetina-3,3'-O-diglucósido. El polen de todas las especies y subespecies de Zea analizadas mostraron patrones muy similares de fenoles acumulados; sin embargo, diferencias en los compuestos menores (ácidos fenólicos y dihidroflavonoides) permitieron discernir variaciones inter e intraespecíficas, aunque la división del género en las dos secciones Luxuriantes y Zea no fue claramente sustentada. La baja variación de los perfiles fenólicos del polen dentro del género Zea apoya la propuesta de que el maíz y 
algunos teocintles son grupos conespecíficos, e indica que la composición fenólica del polen fue altamente conservada en los diferentes taxa de Zea a lo largo del tiempo.

Palabras clave: ácidos fenólicos, flavonoides, género Zea, polen, teocintle.

\begin{abstract}
The variability of the pollen phenol composition of 32 populations of Zea mays subsp. mexicana, Zea mays subsp. parviglumis, Zea mays subsp. mays, Zea diploperennis, Zea perennis, and Zea luxurians from Mexico and Guatemala were analyzed. The phenol profiles were assessed by HPLC-DAD, and UPLC-TOF-MS. A total of 23 phenolics (four phenolic acids, 16 flavonols, and three dihydroflavonoids) were found. Quercetin glycosides (seven derivatives besides the quercetin aglycone itself) were the predominant compounds in the pollen of all analyzed species and subspecies. The major compound in all the samples, including the pollen of maize, was identified as quercetin-3,3'-O-diglucoside. The pollen of all the species and subspecies of Zea examined showed very similar patterns of accumulated phenols; however, variation in the minor compounds (phenolic acids and dihydroflavonoids) allowed to discern some inter- and intraspecific variations, although the split of Zea in the sections Luxuriantes and Zea was not clearly supported. The low level of variability of the pollen phenol profiles throughout the genus Zea supports the proposal that maize and some teosintes are conspecific groups, and indicates that the pollen phenol composition is highly conserved in the different taxa of Zea.
\end{abstract}

Key words: flavonoids, genus Zea, phenolic acids, pollen, teosinte.

\title{
INTRODUCCIÓN
}

El género Zea es nativo de México (Sánchez et al., 2000). De acuerdo con Sánchez et al. (2011), el mismo está formado por ocho taxa agrupados en dos secciones, cinco especies y cuatro subespecies. La sección Luxuriantes Doebley \& Iltis incluye a Zea perennis (Hitchc.) Reeves \& Mangelsdorf, Zea diploperennis Iltis, Doebley \& Guzmán, Zea luxurians (Durieu \& Ascherson) Bird y Zea nicaraguensis Iltis \& Benz). La sección Zea la forman Zea mays subsp. mexicana (Schrader) Iltis, Zea mays subsp. parviglumis Iltis \& Doebley, Zea mays subsp. huehuetenangensis (Iltis \& Doebley) Doebley y Zea mays subsp. mays. 
El único componente cultivado del género, Zea mays subsp. mays, incluye todas las razas y variedades de maíz; todos los demás taxa son colectivamente llamados teocintles (Fig. 1). Dentro de Zea mays subsp. mexicana se reconocen cuatro razas: Chalco, Mesa Central, Durango y Nobogame. La raza Balsas es la única considerada dentro de Zea mays subsp. parviglumis (Doebley, 1990). Nuevas poblaciones de teocintles, que requieren ser ubicadas taxonómicamente, se siguen descubriendo en México y Centro América (Iltis y Benz, 2000; Sánchez et al., 2011).

Los teocintles han tenido una importante influencia en el origen y variabilidad del maíz en la República Mexicana (Wilkes, 2004), y contienen germoplasma valioso para el desarrollo de nuevas variedades de ese cereal, principalmente aquellas tolerantes a enfermedades y estrés ambiental (Nault y Findley, 1981; Cohen y Galinat, 1984). En algunas regiones del país son importantes como forraje, debido a su calidad nutricional, su potencial de producción y sus mecanismos de dispersión y establecimiento (Sánchez-González et al., 1998).

Los flavonoides y los ácidos fenólicos son compuestos sintetizados en prácticamente todos los tejidos de las plantas. El polen es una fuente importante de flavonoles glicósidos y de ácidos fenólicos (Wiermann y Vieth, 1983; Campos, 1997; Almaraz-Abarca et al., 2007). Los perfiles de esas dos clases de compuestos varían entre diferentes grupos de plantas con una tendencia de ser caracteristicos para cada
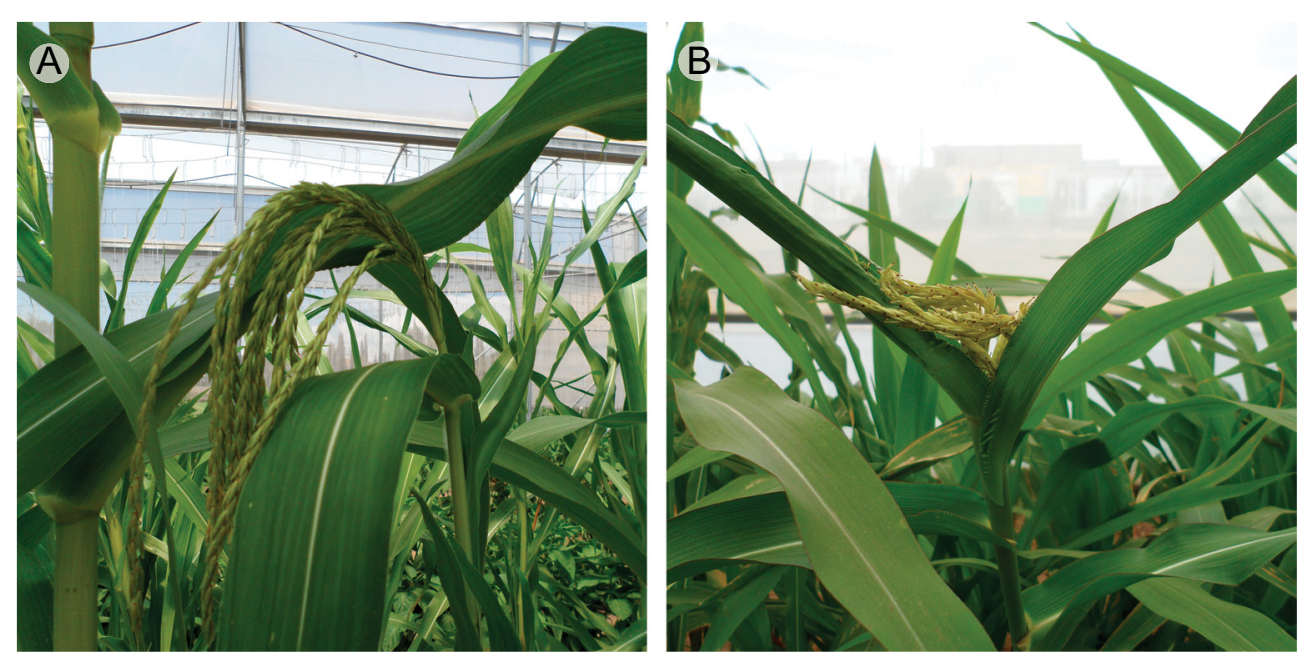

Fig. 1. Dos especies de teocintles, A: Zea mays subsp. parviglumis y B: Zea diploperennis, mostrando las inflorescencias masculinas. 
especie (Campos et al., 1997; Fiasson et al., 1997; Campos et al., 2002; AlmarazAbarca et al., 2004, 2006, 2008).

Los flavonoides y los ácidos fenólicos desempeñan importantes y diversas funciones en las plantas, tales como la protección de los tejidos vegetales contra el daño potencial de la radiación UV (Casati y Walbot, 2003) y contra herbívoros (Lee et al., 1998). Muchos de esos compuestos tienen valiosas propiedades biológicas con implicaciones médicas (Zhang y Cui, 2005).

Los esfuerzos enfocados en determinar la composición fenólica del polen de las especies de Zea han sido escasos, solamente algunos tipos de maíz (Zea mays subsp. mays) han sido estudiados en ese sentido. Redemann y sus colaboradores en 1950 (Larson y Lonergan, 1972) y más tarde Ceska y Styles (1984) determinaron la composición fenólica del polen de maíz y mencionaron la presencia de quercitrina. Ceska y Styles (1984) además reportaron otros ocho derivados glicósidos de quercetina e isoramnetina, sólo un derivado glicósido de canferol (canferol 3-O-glucósido), este último presente en trazas, y resaltaron la ausencia de flavonas en el polen de maíz. En el presente trabajo se determinó, por cromatografía líquida de alta presión, con detector de arreglo de diodos (HPLC-DAD) y cromatografía líquida de ultra presión acoplada a espectrometría de masas de tiempo de vuelo (UPLC-TOF-MS), la variabilidad de la composición de flavonoides y ácidos fenólicos del polen de Zea mays subsp. mexicana, Zea mays subs. parviglumis, Zea mays subsp. mays, Zea diploperennis, Zea perennis y Zea luxurians de México y Guatemala. Se presentan las implicaciones taxonómicas de la variación de los perfiles fenólicos y la importancia del polen de las especies de Zea como fuente de flavonoides.

\section{MATERIALES Y MÉTODOS}

Material vegetal

El material genético incluido en el presente estudio consistió de 32 poblaciones de Zea mays subsp. mexicana, Zea mays subsp. parviglumis, Zea mays subsp. mays, Zea diploperennis, Zea perennis y Zea luxurians de México y Guatemala. En el año 2011 se cultivaron diez plantas de cada población bajo condiciones de invernadero en el Centro Interdisciplinario de Investigación para el Desarrollo Integral Regional, del Instituto Politécnico Nacional, Unidad Durango (CIIDIR IPN Durango), en Durango, México. Las semillas, excepto las de Zea mays subsp. mays (de una variedad criolla, proporcionadas por un productor de Durango, México), fueron donadas por el Banco de Germoplasma de la Universidad de Guada- 
lajara, Jalisco. La información geográfica de todas las poblaciones estudiadas se presenta en el Cuadro 1.

Preparación de las muestras

Las muestras de polen se colectaron directamente de las anteras de 10 plantas adultas de cada una de las 32 poblaciones. El polen de las 10 plantas de una misma población se combinó y se analizó de manera independiente. El polen colectado se almacenó a $-20{ }^{\circ} \mathrm{C}$ hasta su uso.

Reactivos químicos

El acetonitrilo (grado HPLC), agua (grado HPLC), etanol (grado HPLC) y acetato de etilo (grado analítico) se compraron a J. T. Baker (Xalostoc, México). El ácido acético, hidróxido de sodio, 2-propanol, quercetina, quercitrina (quercetin3-ramnosido), canferol-3-glucósido, y ácido caféico se adquirieron de Sigma-Aldrich (St. Louis, Mo, USA). El canferol-3,7-O-diglucósido, quercetina-3-O-[ramnosil-(1-6) galactósido], canferol-3-O-[ramnosil (1-6) glucósido] se consiguieron en Apin Chemicals Limited (UK).

Preparación de extractos fenólicos

Los extractos fenólicos de polen se prepararon de acuerdo con la técnica de Markham y Campos (1996), combinando $100 \mathrm{mg}$ de polen con $1 \mathrm{~mL}$ de una solución de etanol a $50 \%(\mathrm{v} / \mathrm{v})$ y sonicando durante $60 \mathrm{~min}$. Las mezclas resultantes se centrifugaron a $5000 \mathrm{rpm}$ durante $10 \mathrm{~min}$. Las alícuotas de los sobrenadantes se usaron para los análisis de HPLC-DAD y UPLC-TOF-MS.

\section{Análisis de HPLC-DAD}

Los perfiles de HPLC-DAD de flavonoides y ácidos fenólicos se determinaron de acuerdo al protocolo descrito por Campos y Markham (2007). Las alícuotas $(100 \mu \mathrm{L})$ de cada muestra se analizaron en un equipo HPLC Perkin Elmer Series 200 HPLC y una columna Perkin Elmer Brownlee Validated C18 (4.6 x 250 mm, $5 \mu \mathrm{m})$. El solvente A fue agua acidificada (ajustada a pH 2.5 con ácido ortofosfórico) y el solvente B fue acetonitrilo, mezclados de acuerdo con el siguiente gradiente lineal: iniciando con $100 \%$ de A, disminuyendo a $91 \%$ a los $12 \mathrm{~min}$, a $87 \%$ a los 20 , a $67 \%$ a los 32 y a $57 \%$ a los $42 \mathrm{~min}$, y manteniendo ese nivel hasta completar $60 \mathrm{~min}$ de análisis. La velocidad de flujo fue de $0.8 \mathrm{~mL} / \mathrm{min}$, a temperatura ambiente. Los cromatogramas se registraron a 260 y $340 \mathrm{~nm}$. Los datos espectrales para todos los picos se registraron en el intervalo de 220 a 400 nm, usando un detector de arreglo de diodos (Perkin Elmer Series 200). La 
información estructural se obtuvo por comparación directa de los tiempos de retención y los espectros UV, de cada compuesto resuelto en los cromatogramas con los correspondientes a los compuestos de referencia, y por comparación de esos parámetros con la información compilada por Mabry et al. (1970) y Campos y Markham (2007).

\section{Análisis de UPLC-TOF-MS}

Estos análisis se realizaron en un sistema Waters Acquity UPLC (Waters, Millford, MA). Se usó una columna Zorbax Eclipse Plus C18 $(1.8 \mu \mathrm{m}, 150 \times 4.6 \mathrm{~mm})$ UPLC. La separación de los compuestos se realizó a $25^{\circ} \mathrm{C}$, con un programa de elución en gradiente, y una velocidad de flujo de $0.8 \mathrm{~mL} / \mathrm{min}$. El volumen de inyección fue de $10 \mu \mathrm{L}$. La fase móvil consistió de agua y ácido acético (15\%) como solvente A, y acetonitrilo como solvente B. Se aplicó el siguiente gradiente lineal: 0 min, 5\% de B; $10 \mathrm{~min}, 30 \%$ de B; $12 \mathrm{~min}, 33 \%$ de B; $17 \mathrm{~min}, 38 \%$ de B; $20 \mathrm{~min}, 50 \%$ de B; $23 \mathrm{~min}, 95 \%$ de $\mathrm{B}$; y $25 \mathrm{~min}, 5 \%$ de $\mathrm{B}$. Las condiciones iniciales se mantuvieron durante 10 min más.

El sistema UPLC estuvo acoplado a un espectrómetro de masas de tiempo de vuelo (micrOTOF ${ }^{\mathrm{TM}}$, Bruker Daltonics GmbH, Bremen, Alemania), equipado con una interfase ESI modelo G1607A (Agilent Technologies), operando en modo ión negativo. En ese estado se requirió un "splitter" tipo T (split = 1:3) para el acoplamiento con el detector de masas cuando el flujo en el detector TOF fue de $0.2 \mathrm{~mL} / \mathrm{min}$ para lograr resultados reproducibles y aspersión estable. Así, en el presente estudio el flujo que llegó al detector ESI-TOF-MS fue de $0.2 \mathrm{~mL} / \mathrm{min}$. Los valores óptimos de los parámetros de fuente fueron los siguientes: voltaje capilar, $+4 \mathrm{kV}$; temperatura de secado de gas, $210^{\circ} \mathrm{C}$; flujo de gas, $8 \mathrm{~L} / \mathrm{min}$; presión de gas nebulizante, 2 bar; "end-plate offset", $-0.5 \mathrm{kV}$. Las condiciones de transferencia fueron: salida capilar, -120 V; "skimmer" 1, -40 V; hexapolo 1, - $23 \mathrm{~V}$; RF hexapolo, $50 \mathrm{Vpp}$; "skimmer" 2, $-22.5 \mathrm{~V}$. Los parámetros de fuente y transferencia se optimizaron para asegurar buena sensibilidad, alcanzar una resolución razonable en el intervalo de masas de los compuestos blanco (50-1100 m/z) y mejorar el comportamiento de la ionización.

La calibración externa del espectrómetro de masas se llevó a cabo con una solución conteniendo hidróxido de sodio $5 \mathrm{mM}$ en agua/2-propanol $(1 / 1, \mathrm{v} / \mathrm{v})$, con ácido acético a $0.2 \%$, en modo de regresión cuadrática de calibración de alta precisión (HPC). Con este método se logró una curva de calibración exacta basada en diversos grupos (clusters) de masas, cada una difiriendo en $82 \mathrm{Da}\left(\mathrm{C}_{2} \mathrm{H}_{3} \mathrm{NaO}_{2}\right)$. La solución de calibración se inyectó al inicio del análisis usando una bomba Cole Palmer (Vernon Hills, Illinois, USA) y todos los espectros se calibraron antes de la caracterización de fenoles. Los datos de masa exacta para los iones moleculares 
se procesaron con el programa Data Analysis 4.0 (Bruker Daltonics, Bremen, Alemania), el cual proporcionó una lista de fórmulas elementales posibles, usando el editor Generate Molecular Formula ${ }^{\mathrm{TM}}$. Ese editor se basa en un algoritmo CHNO que proporciona funcionalidades estándares tales como intervalo elemental mínimo/máximo, equivalentes anillo y doble enlace, y una comparación sofisticada de patrón teórico y medido de isótopos (valor $\mathrm{mSigma}$ ) para incrementar la confianza en la fórmula molecular sugerida. De acuerdo con la literatura, el nivel aceptado de umbral de exactitud para confirmar la composición elemental se estableció en 5 ppm para la mayoría de los compuestos (Gross, 2010).

Análisis de datos

Los perfiles fenólicos individuales se construyeron con todos los compuestos presentes en los cromatogramas HPLC-DAD y UPLC-TOF-MS; cada uno se consideró como un carácter químico individual y con ellos se construyó una matriz binaria de presencia (1)-ausencia (0). Se generó una matriz de distancias entre poblaciones, basada en el coeficiente de disimilitud de Jaccard, y un análisis de agrupamiento, usando el método de incremento en la suma de cuadrados (Clustan Graphics 8). El número óptimo de grupos (clusters) se estimó usando el procedimiento de validación de árbol, por medio de permutación aleatoria de datos originales, que compara un árbol obtenido por un juego de datos con la familia de árboles generados por permutación aleatoria del mismo juego de datos (Wishart, 2006).

Cuadro 1. Información geográfica de las especies, subespecies y poblaciones de Zea analizadas en el presente estudio, todas originarias de México, excepto $Z$. luxurians, que fue de Guatemala.

\begin{tabular}{|c|c|c|c|c|c|c|}
\hline Especie & Localidad & $\begin{array}{l}\text { Latitud } \\
(\mathrm{N})\end{array}$ & $\begin{array}{l}\text { Longitud } \\
\text { (O) }\end{array}$ & $\begin{array}{l}\text { Altitud } \\
(\mathrm{m})\end{array}$ & $\begin{array}{l}\text { Número de } \\
\text { población }\end{array}$ & $\begin{array}{l}\text { Año de } \\
\text { colecta }\end{array}$ \\
\hline $\begin{array}{l}\text { Z. mays subsp. } \\
\text { mexicana, raza } \\
\text { Chalco }\end{array}$ & $\begin{array}{l}\text { Chapultepec, } \\
\text { Estado de México }\end{array}$ & $19^{\circ} 12^{\prime} 12^{\prime \prime}$ & $99^{\circ} 34^{\prime} 3 "$ & 2602 & 615 & 2007 \\
\hline $\begin{array}{l}\text { Z. mays subsp. } \\
\text { mexicana, raza } \\
\text { Chalco }\end{array}$ & $\begin{array}{l}\text { km } 1 \text { Aljojuca- } \\
\text { Santa María } \\
\text { Coatepec, } \\
\text { Aljojuca, Puebla }\end{array}$ & $19^{\circ} 5^{\prime} 51^{\prime \prime}$ & $97^{\circ} 33^{\prime} 6^{\prime \prime}$ & 2437 & 623 & 2007 \\
\hline $\begin{array}{l}\text { Z. mays subsp. } \\
\text { mexicana, raza } \\
\text { Chalco }\end{array}$ & $\begin{array}{l}\text { San Antonio } \\
\text { Zoyatzingo, } \\
\text { Amecameca, } \\
\text { Estado de México }\end{array}$ & $19^{\circ} 4^{\prime} 54^{\prime \prime}$ & $98^{\circ} 46^{\prime} 35^{\prime \prime}$ & 2468 & 635 & 2007 \\
\hline
\end{tabular}


Cuadro 1. Continuación.

\begin{tabular}{|c|c|c|c|c|c|c|}
\hline Especie & Localidad & $\begin{array}{l}\text { Latitud } \\
(\mathrm{N})\end{array}$ & $\begin{array}{l}\text { Longitud } \\
\text { (O) }\end{array}$ & $\begin{array}{l}\text { Altitud } \\
(\mathrm{m})\end{array}$ & $\begin{array}{c}\text { Número de } \\
\text { población }\end{array}$ & $\begin{array}{l}\text { Año de } \\
\text { colecta }\end{array}$ \\
\hline $\begin{array}{l}\text { Z. mays subsp. } \\
\text { mexicana, raza } \\
\text { Chalco }\end{array}$ & $\begin{array}{l}\text { Miraflores-La } \\
\text { Candelaria } \\
\text { Tlapala, Chalco, } \\
\text { Estado de México }\end{array}$ & $19^{\circ} 13^{\prime} 57^{\prime \prime}$ & $98^{\circ} 50^{\prime} 3^{\prime \prime}$ & 2280 & 638 & 2007 \\
\hline $\begin{array}{l}\text { Z. mays subsp. } \\
\text { mexicana, raza } \\
\text { Central Plateau }\end{array}$ & $\begin{array}{l}\text { Cerro Churintzio, } \\
\text { Churintzio, } \\
\text { Michoacán }\end{array}$ & $20^{\circ} 9^{\prime} 25^{\prime \prime}$ & $102^{\circ} 3^{\prime} 35^{\prime \prime}$ & 1949 & 426 & 2002 \\
\hline $\begin{array}{l}\text { Z. mays subsp. } \\
\text { mexicana, raza } \\
\text { Central Plateau }\end{array}$ & $\begin{array}{l}\text { Uriangato, } \\
\text { Uriangato, } \\
\text { Guanajuato }\end{array}$ & $20^{\circ} 10^{\prime} 8^{\prime \prime}$ & $101^{\circ} 9^{\prime} 22^{\prime \prime}$ & 1880 & 447 & 2002 \\
\hline $\begin{array}{l}\text { Z. mays subsp. } \\
\text { mexicana, raza } \\
\text { Central Plateau }\end{array}$ & $\begin{array}{l}\text { San Agustín del } \\
\text { Maíz, Copándaro, } \\
\text { Michoacán }\end{array}$ & $19^{\circ} 53^{\prime} 27^{\prime \prime}$ & $101^{\circ} 10^{\prime} 46^{\prime \prime}$ & 1855 & 450 & 2002 \\
\hline $\begin{array}{l}\text { Z. mays subsp. } \\
\text { mexicana, raza } \\
\text { Central Plateau }\end{array}$ & $\begin{array}{l}\text { Potrero El } \\
\text { Tepalcate, Nombre } \\
\text { de Dios, Durango }\end{array}$ & $24^{\circ} 2^{\prime} 32^{\prime \prime}$ & $104^{\circ} 16^{\prime} 47^{\prime \prime}$ & 1870 & 705 & 2009 \\
\hline $\begin{array}{l}\text { Z. mays subsp. } \\
\text { mexicana, raza } \\
\text { Central Plateau }\end{array}$ & $\begin{array}{l}\text { Puente Gavilanes, } \\
\text { Durango, Durango }\end{array}$ & $24^{\circ} 1^{\prime} 12^{\prime \prime}$ & $104^{\circ} 29^{\prime} 16^{\prime \prime}$ & 1868 & 710 & 2009 \\
\hline $\begin{array}{l}\text { Z. mays subsp. } \\
\text { mexicana, raza } \\
\text { Nobogame }\end{array}$ & $\begin{array}{l}\text { Arroyo } \\
\text { Tarahumares, } \\
\text { Guadalupe y } \\
\text { Calvo, Chihuahua }\end{array}$ & $26^{\circ} 12^{\prime} 58^{\prime \prime}$ & $106^{\circ} 56^{\prime} 33^{\prime \prime}$ & 1928 & 607 & 2007 \\
\hline $\begin{array}{l}\text { Z. mays subsp. } \\
\text { parviglumis, raza } \\
\text { Balsas }\end{array}$ & $\begin{array}{l}\text { San Lorenzo, } \\
\text { Ejutla, Jalisco }\end{array}$ & $19^{\circ} 57^{\prime} 6^{\prime \prime}$ & $103^{\circ} 59^{\prime} 3^{\prime \prime}$ & 1000 & 201 & 2007 \\
\hline $\begin{array}{l}\text { Z. mays subsp. } \\
\text { parviglumis, raza } \\
\text { Balsas }\end{array}$ & $\begin{array}{l}\text { El Rodeo, } \\
\text { Tolimán, Jalisco }\end{array}$ & $19^{\circ} 33^{\prime} 0^{\prime \prime}$ & $104^{\circ} 3^{\prime} 0^{\prime \prime}$ & 1462 & 232 & 2007 \\
\hline $\begin{array}{l}\text { Z. mays subsp. } \\
\text { parviglumis, raza } \\
\text { Balsas }\end{array}$ & $\begin{array}{l}\text { Amatlán de } \\
\text { Quetzalcoatl, } \\
\text { Tepoztlán, } \\
\text { Morelos }\end{array}$ & $18^{\circ} 58^{\prime} 30^{\prime \prime}$ & $99^{\circ} 1^{\prime} 49^{\prime \prime}$ & 1654 & 474 & 2003 \\
\hline $\begin{array}{l}\text { Z. mays subsp. } \\
\text { parviglumis, raza } \\
\text { Balsas }\end{array}$ & $\begin{array}{l}\text { San Cristobal } \\
\text { Honduras, Oaxaca }\end{array}$ & $16^{\circ} 19^{\prime} 26^{\prime \prime}$ & $97^{\circ} 1^{\prime} 57^{\prime \prime}$ & 590 & 483 & 2003 \\
\hline $\begin{array}{l}\text { Z. mays subsp. } \\
\text { parviglumis, raza } \\
\text { Balsas }\end{array}$ & $\begin{array}{l}\text { Puerto de La } \\
\text { Cruz, Carácuaro, } \\
\text { Michoacán }\end{array}$ & $18^{\circ} 57^{\prime} 47^{\prime \prime}$ & $101^{\circ} 3^{\prime} 27^{\prime \prime}$ & 870 & 517 & 2003 \\
\hline
\end{tabular}


Cuadro 1. Continuación.

\begin{tabular}{|c|c|c|c|c|c|c|}
\hline Especie & Localidad & $\begin{array}{l}\text { Latitud } \\
(\mathrm{N})\end{array}$ & $\begin{array}{l}\text { Longitud } \\
\text { (O) }\end{array}$ & $\begin{array}{l}\text { Altitud } \\
(\mathrm{m})\end{array}$ & $\begin{array}{c}\text { Número de } \\
\text { población }\end{array}$ & $\begin{array}{l}\text { Año de } \\
\text { colecta }\end{array}$ \\
\hline $\begin{array}{l}\text { Z. mays subsp. } \\
\text { parviglumis, raza } \\
\text { Balsas }\end{array}$ & $\begin{array}{l}\text { Los Cimientos, } \\
\text { Villa Purificación, } \\
\text { Jalisco }\end{array}$ & $19^{\circ} 42^{\prime} 15^{\prime \prime}$ & $104^{\circ} 49^{\prime} 8^{\prime \prime}$ & 552 & 546 & 2003 \\
\hline $\begin{array}{l}\text { Z. mays subsp. } \\
\text { parviglumis, raza } \\
\text { Balsas }\end{array}$ & $\begin{array}{l}\text { Plan de los } \\
\text { Timbres, Huitzuco } \\
\text { de los Figueroa, } \\
\text { Guerrero }\end{array}$ & $18^{\circ} 15^{\prime} 9^{\prime \prime}$ & $99^{\circ} 14^{\prime} 1 "$ & 1183 & 643 & 2007 \\
\hline $\begin{array}{l}\text { Z. mays subsp. } \\
\text { parviglumis, raza } \\
\text { Balsas }\end{array}$ & $\begin{array}{l}\text { Vista Hermosa, } \\
\text { Olinalá, Guerrero }\end{array}$ & $17^{\circ} 45^{\prime} 37^{\prime \prime}$ & $98^{\circ} 46^{\prime} 28^{\prime \prime}$ & 1580 & 646 & 2007 \\
\hline $\begin{array}{l}\text { Z. mays subsp. } \\
\text { parviglumis, raza } \\
\text { Balsas }\end{array}$ & $\begin{array}{l}\text { Camino Vista } \\
\text { Hermosa- } \\
\text { Colotlipa, } \\
\text { Quechultenango, } \\
\text { Guerrero }\end{array}$ & $17^{\circ} 26^{\prime} 16^{\prime \prime}$ & $99^{\circ} 12^{\prime} 5^{\prime \prime}$ & 945 & 650 & 2007 \\
\hline $\begin{array}{l}\text { Z. mays subsp. } \\
\text { parviglumis, raza } \\
\text { Balsas }\end{array}$ & $\begin{array}{l}\text { El Rincón, } \\
\text { Chilpancingo } \\
\text { de los Bravo, } \\
\text { Guerrero }\end{array}$ & $17^{\circ} 17^{\prime} 13^{\prime \prime}$ & $99^{\circ} 28^{\prime} 59^{\prime \prime}$ & 740 & 654 & 2007 \\
\hline $\begin{array}{l}\text { Z. mays subsp. } \\
\text { parviglumis, raza } \\
\text { Balsas }\end{array}$ & $\begin{array}{l}\text { El Salado, } \\
\text { Mochitlán, } \\
\text { Guerrero }\end{array}$ & $17^{\circ} 23^{\prime} 48^{\prime \prime}$ & $99^{\circ} 26^{\prime} 12^{\prime \prime}$ & 1150 & 657 & 2007 \\
\hline $\begin{array}{l}\text { Z. mays subsp. } \\
\text { parviglumis, raza } \\
\text { Balsas }\end{array}$ & $\begin{array}{l}\text { Zacatlancillo, } \\
\text { Teloloapan, } \\
\text { Guerrero }\end{array}$ & $18^{\circ} 25^{\prime} 0^{\prime \prime}$ & $99^{\circ} 58^{\prime} 3^{\prime \prime}$ & 1746 & 661 & 2007 \\
\hline $\begin{array}{l}\text { Z. mays subsp. } \\
\text { parviglumis, raza } \\
\text { Balsas }\end{array}$ & $\begin{array}{l}\text { Ixcateopan, } \\
\text { Guerrero }\end{array}$ & $18^{\circ} 30^{\prime} 16^{\prime \prime}$ & $99^{\circ} 47^{\prime \prime} 4^{\prime \prime}$ & 1891 & 666 & 2007 \\
\hline $\begin{array}{l}\text { Z. mays subsp. } \\
\text { parviglumis, raza } \\
\text { Balsas }\end{array}$ & $\begin{array}{l}\text { Oxtotitlán, } \\
\text { Teloloapan, } \\
\text { Guerrero }\end{array}$ & $18^{\circ} 10^{\prime} 41^{\prime \prime}$ & $99^{\circ} 56^{\prime} 00^{\prime \prime}$ & 1098 & 669 & 2007 \\
\hline $\begin{array}{l}\text { Z. mays subsp. } \\
\text { parviglumis, raza } \\
\text { Balsas }\end{array}$ & $\begin{array}{l}\text { Huixtitla, } \\
\text { Amatepec, Estado } \\
\text { de México }\end{array}$ & $18^{\circ} 38^{\prime} 26^{\prime \prime}$ & $100^{\circ} 21^{\prime} 24^{\prime \prime}$ & 1008 & 674 & 2007 \\
\hline $\begin{array}{l}\text { Z. mays subsp. } \\
\text { parviglumis, raza } \\
\text { Balsas }\end{array}$ & $\begin{array}{l}\text { km } 109 \text { Tejupilco- } \\
\text { Altamirano, } \\
\text { Michoacán }\end{array}$ & $18^{\circ} 53^{\prime} 41^{\prime \prime}$ & $100^{\circ} 12^{\prime} 32^{\prime \prime}$ & 1357 & 679 & 2007 \\
\hline
\end{tabular}


Cuadro 1. Continuación.

\begin{tabular}{|c|c|c|c|c|c|c|}
\hline Especie & Localidad & $\begin{array}{l}\text { Latitud } \\
(\mathrm{N})\end{array}$ & $\begin{array}{l}\text { Longitud } \\
\text { (O) }\end{array}$ & $\begin{array}{l}\text { Altitud } \\
(\mathrm{m})\end{array}$ & $\begin{array}{c}\text { Número de } \\
\text { población }\end{array}$ & $\begin{array}{l}\text { Año de } \\
\text { colecta }\end{array}$ \\
\hline $\begin{array}{l}\text { Z. mays subsp. } \\
\text { parviglumis, raza } \\
\text { Balsas }\end{array}$ & $\begin{array}{l}\text { Quechendio, } \\
\text { Huetamo, } \\
\text { Michoacán }\end{array}$ & $18^{\circ} 48^{\prime} 18^{\prime \prime}$ & $100^{\circ} 56^{\prime} 46^{\prime \prime}$ & 631 & 684 & 2007 \\
\hline $\begin{array}{l}\text { Zea } \\
\text { diploperennis }\end{array}$ & $\begin{array}{l}\text { Las Joyas, } \\
\text { Cuautitlán de } \\
\text { García B., Jalisco }\end{array}$ & $19^{\circ} 35^{\prime} 26^{\prime \prime}$ & $104^{\circ} 16^{\prime} 41^{\prime \prime}$ & 1870 & 551 & 2003 \\
\hline $\begin{array}{l}\text { Zea } \\
\text { diploperennis }\end{array}$ & $\begin{array}{l}\text { San Andrés } \\
\text { Milpillas, } \\
\text { Huajicori, Nayarit }\end{array}$ & $22^{\circ} 51^{\prime} 26^{\prime \prime}$ & $105^{\circ} 6^{\prime} 57^{\prime \prime}$ & 1400 & 692 & 2008 \\
\hline Zea luxurians & $\begin{array}{l}\text { km } 162 \text { Agua } \\
\text { Blanca-Ipala, Agua } \\
\text { Blanca, Jutiapa }\end{array}$ & $14^{\circ} 31^{\prime} 32^{\prime \prime}$ & $89^{\circ} 39^{\prime} 45^{\prime \prime}$ & 895 & G3 & 2004 \\
\hline Zea perennis & $\begin{array}{l}\text { Piedra Ancha, San } \\
\text { Gabriel, Jalisco }\end{array}$ & $19^{\circ} 38^{\prime} 7^{\prime \prime}$ & $103^{\circ} 34^{\prime} 47^{\prime \prime}$ & 2140 & 694 & 2008 \\
\hline
\end{tabular}

\section{RESULTADOS Y DISCUSIÓN}

Composición fenólica del polen

Un total de 23 compuestos se resolvieron por los análisis de HPLC-DAD y UPLC-TOF-MS, de acuerdo con sus tiempos de retención (TR), las características de sus espectros UV, los datos de sus espectros de masas, y los datos proporcionados por las compilaciones de Mabry et al. (1970) y Campos y Markham (2007). En el Cuadro 2 se muestran los $\mathrm{TR}_{1}$ y datos espectrales UV del análisis de HPLC-DAD, y en el Cuadro 3 los $\mathrm{TR}_{2} \mathrm{y}$ datos de los espectros de masas obtenidos del análisis de UPLC-TOF-MS.

Las estructuras propuestas de los compuestos resueltos por UPLC-TOF-MS se muestran en las Figs. 2 y 3 . El análisis reveló cuatro ácidos fenólicos, saflomina A (9) (Iswaldi et al., 2011), ácido ferúlico (14) (Gardana et al., 2007), y dos compuestos no identificados (22 y 23); 16 flavonoles, determinados como quercetina-3,7- $O$-diglucósido (1) (Vallejo at al., 2004), quercetina-3- $O$-arabinosilglucósido (2), quercetina-3-soforósido-7-glucósido (3) (Rochfort et al., 2006), quercetina-3,3'-O-diglucósido (4) (Morikawa et al., 2009), isoramnetina-3-O-gentobiósido (5) (Dahia et al., 2009), un flavonol glicósido no identificado (6), quercetina-3- $O$-ramnoglucósido (7), canferol-3-O- $\beta$-ramnoglucósido (8), isoramnetina-3- $O$ - $\beta$-ramnoglucósido (10), 
Cuadro 2. Descripción de los compuestos fenólicos encontrados por el análisis de HPLC$\mathrm{DAD}$ en los extractos de polen de 32 poblaciones de Zea.

\begin{tabular}{|c|c|c|c|c|}
\hline $\begin{array}{l}\text { Número de } \\
\text { compuesto }\end{array}$ & $\mathrm{TR}_{1}(\mathrm{X} \pm \mathrm{SD})$ & $\lambda \max (\mathrm{nm})$ & $\begin{array}{c}\text { Tipo de } \\
\text { compuesto }\end{array}$ & Presencia \\
\hline 1 & $27.800 \pm 0.273$ & $\begin{array}{c}256,268 \mathrm{sh}, \\
355\end{array}$ & $\begin{array}{l}\text { Flavonol } \\
\text { glicósido }\end{array}$ & Todos los taxa \\
\hline 2 & $28.176 \pm 0.250$ & $\begin{array}{c}255,268 \mathrm{sh} \\
354\end{array}$ & $\begin{array}{l}\text { Flavonol } \\
\text { glicósido }\end{array}$ & $\begin{array}{l}\text { Subsp. parviglumis, subsp. } \\
\text { mexicana, Z. luxurians, maíz }\end{array}$ \\
\hline 3 & $31.465 \pm 0.250$ & $\begin{array}{l}250 \mathrm{sh}, 266 \\
345\end{array}$ & $\begin{array}{l}\text { Flavonol } \\
\text { glicósido }\end{array}$ & Todos los taxa \\
\hline 4 & $33.353 \pm 0.200$ & $\begin{array}{c}253 \mathrm{sh}, 267 \\
345\end{array}$ & $\begin{array}{l}\text { Flavonol } \\
\text { glicósido }\end{array}$ & Todos los taxa \\
\hline 5 & $34.142 \pm 0.170$ & $\begin{array}{l}253,266 \\
346\end{array}$ & $\begin{array}{l}\text { Flavonol } \\
\text { glicósido }\end{array}$ & Todos los taxa \\
\hline 6 & $34.412 \pm 0.171$ & $\begin{array}{l}254,267 \\
349\end{array}$ & $\begin{array}{l}\text { Flavonol } \\
\text { glicósido }\end{array}$ & $\begin{array}{l}\text { Algunas poblaciones de } \\
\text { subsp. parviglumis y subsp. } \\
\text { mexicana }\end{array}$ \\
\hline 7 & $35.259 \pm 0.174$ & $\begin{array}{l}255,266 \mathrm{sh} \\
296 \mathrm{sh}, 354\end{array}$ & $\begin{array}{l}\text { Flavonol } \\
\text { glicósido }\end{array}$ & Todos los taxa \\
\hline 8 & $37.102 \pm 0.102$ & $\begin{array}{l}266,300 \mathrm{sh} \\
350\end{array}$ & $\begin{array}{l}\text { Flavonol } \\
\text { glicósido }\end{array}$ & $\begin{array}{l}\text { Z. luxurians, maíz, } \\
\text { algunas poblaciones de } \\
\text { subsp. mexicana y subsp. } \\
\text { parviglumis }\end{array}$ \\
\hline 9 & $36.025 \pm 0.000$ & $\begin{array}{c}243 \mathrm{sh}, \\
268 \mathrm{sh}, \\
290 \mathrm{sh}, 322\end{array}$ & Ácido fenólico & Z. perennis \\
\hline 10 & $37.246 \pm 0.125$ & $\begin{array}{l}254,269 \mathrm{sh} \\
298 \mathrm{sh}, 354\end{array}$ & $\begin{array}{l}\text { Flavonol } \\
\text { glicósido }\end{array}$ & Todos los taxa \\
\hline 11 & $37.369 \pm 0.083$ & $\begin{array}{l}254,268 \mathrm{sh} \\
295 \mathrm{sh}, 354\end{array}$ & $\begin{array}{l}\text { Flavonol } \\
\text { glicósido }\end{array}$ & Z. diploperennis \\
\hline 12 & $37.876 \pm 0.195$ & $\begin{array}{l}255,266 \mathrm{sh} \\
297 \mathrm{sh}, 355\end{array}$ & $\begin{array}{l}\text { Flavonol } \\
\text { glicósido }\end{array}$ & Todos los taxa \\
\hline 13 & $38.756 \pm 0.000$ & $\begin{array}{l}254,269 \mathrm{sh} \\
294 \mathrm{sh}, 355\end{array}$ & $\begin{array}{l}\text { Flavonol } \\
\text { glicósido }\end{array}$ & Z. diploperennis \\
\hline 14 & $39.34 \pm 0.000$ & $\begin{array}{c}243 \mathrm{sh}, \\
268 \mathrm{sh}, \\
293 \mathrm{sh}, 325\end{array}$ & Ácido fenólico & Z. perennis \\
\hline 15 & $40.19 \pm 0.000$ & $\begin{array}{l}254,264 \mathrm{sh} \\
293 \mathrm{sh}, 348\end{array}$ & $\begin{array}{l}\text { Flavonol } \\
\text { glicósido }\end{array}$ & $\begin{array}{l}\text { Z. diploperennis y } Z \text {. } \\
\text { luxurians }\end{array}$ \\
\hline 16 & $40.704 \pm 0.000$ & $\begin{array}{l}255,267 \mathrm{sh} \\
296 \mathrm{sh}, 355\end{array}$ & $\begin{array}{l}\text { Flavonol } \\
\text { glicósido }\end{array}$ & $\begin{array}{l}\text { Z. perennis, una población } \\
\text { de subsp. parviglumis }\end{array}$ \\
\hline
\end{tabular}


Cuadro 2. Continuación.

\begin{tabular}{|c|c|c|c|c|}
\hline $\begin{array}{l}\text { Número de } \\
\text { compuesto }\end{array}$ & $\mathrm{TR}_{1}(\mathrm{X} \pm \mathrm{SD})$ & $\lambda \max (\mathrm{nm})$ & $\begin{array}{c}\text { Tipo de } \\
\text { compuesto }\end{array}$ & Presencia \\
\hline 17 & $45.356 \pm 0.274$ & $\begin{array}{c}255 \mathrm{sh}, 272 \\
340\end{array}$ & $\begin{array}{l}\text { Flavonol } \\
\text { glicósido }\end{array}$ & $\begin{array}{l}\text { Algunas poblaciones de } \\
\text { subsp. parviglumis, subsp. } \\
\text { mexicana, Z. diploperennis }\end{array}$ \\
\hline 18 & $48.785 \pm 0.000$ & $\begin{array}{l}255,270 \mathrm{sh} \\
300 \mathrm{sh}, 372\end{array}$ & Flavonol & $\begin{array}{l}\text { Z. diploperennis } \\
\text { Z. perennis }\end{array}$ \\
\hline 19 & $54.558 \pm 0.273$ & $288,330 \mathrm{sh}$ & Dihidroflavonoide & Z. diploperennis \\
\hline 20 & $56.082 \pm 0.022$ & $286,353 \mathrm{sh}$ & Dihidroflavonoide & $\begin{array}{l}\text { Una población de subsp. } \\
\text { parviglumis }\end{array}$ \\
\hline 21 & $56.621 \pm 0.103$ & $287,338 \mathrm{sh}$ & Dihidroflavonoide & $\begin{array}{l}\text { Algunas poblaciones de } \\
\text { subsp. parviglumis, algunas } \\
\text { poblaciones de subsp. } \\
\text { mexicana, Z. luxurians }\end{array}$ \\
\hline 22 & $56.818 \pm 0.106$ & $\begin{array}{c}\text { 249sh, } \\
\text { 296sh, } 328\end{array}$ & Ácido fenólico & $\begin{array}{l}\text { Algunas poblaciones de } \\
\text { subsp. parviglumis, algunas } \\
\text { poblaciones de subsp. } \\
\text { mexicana }\end{array}$ \\
\hline 23 & $61.436 \pm 0.173$ & $\begin{array}{c}246 \mathrm{sh} \\
295 \mathrm{sh}, 327\end{array}$ & Ácido fenólico & $\begin{array}{l}\text { Algunas poblaciones de } \\
\text { subsp. parviglumis, algunas } \\
\text { poblaciones de subsp. } \\
\text { mexicana }\end{array}$ \\
\hline
\end{tabular}

6-metoxiquercetina (11) (Zhang et al., 2007), quercetina-3-O-galactósido (12) (Hiroaka et al., 1987), quercetina-3- $\alpha$-L-arabinofuranósido (13) (Schieber et al., 2003), quercetina-ramnósido (15) (Ferracane et al., 2010), isoramnetina-3-O-D-glucósido (16) (Dahia et al., 2009), un flavonol glicósido no identificado (17), y quercetina (18) (Tao et al., 2011); y tres dihidroflavonoides, naringenina (19) (Tao et al., 2011), y dos no determinados (20 y 21). Entre los flavonoles, los derivados glicósidos de quercetina fueron los compuestos fenólicos más comunes y abundantes en el polen de todas las especies y subespecies analizadas de Zea. El compuesto principal (el encontrado a mayor concentración) en todas las muestras fue 4 (quercetina-3,3'-O-diglucósido). El único derivado de canferol (8) (canferol-3-O- $\beta$-ramnoglucósido) se encontró en 25 de las 32 muestras de polen $(201,232,426,447,474,450,483,517,623,635$, $638,646,650,654,657,661,666,669,679,684,694,705,710$, G3, y maíz). Estos resultados están parcialmente de acuerdo con los de Ceska y Styles (1984), quienes reportaron a la quercetina-3,3'-O-diglucósido como el flavonoide principal en el po- 
Almaraz-Abarca et al.: Fenoles del polen del género Zea

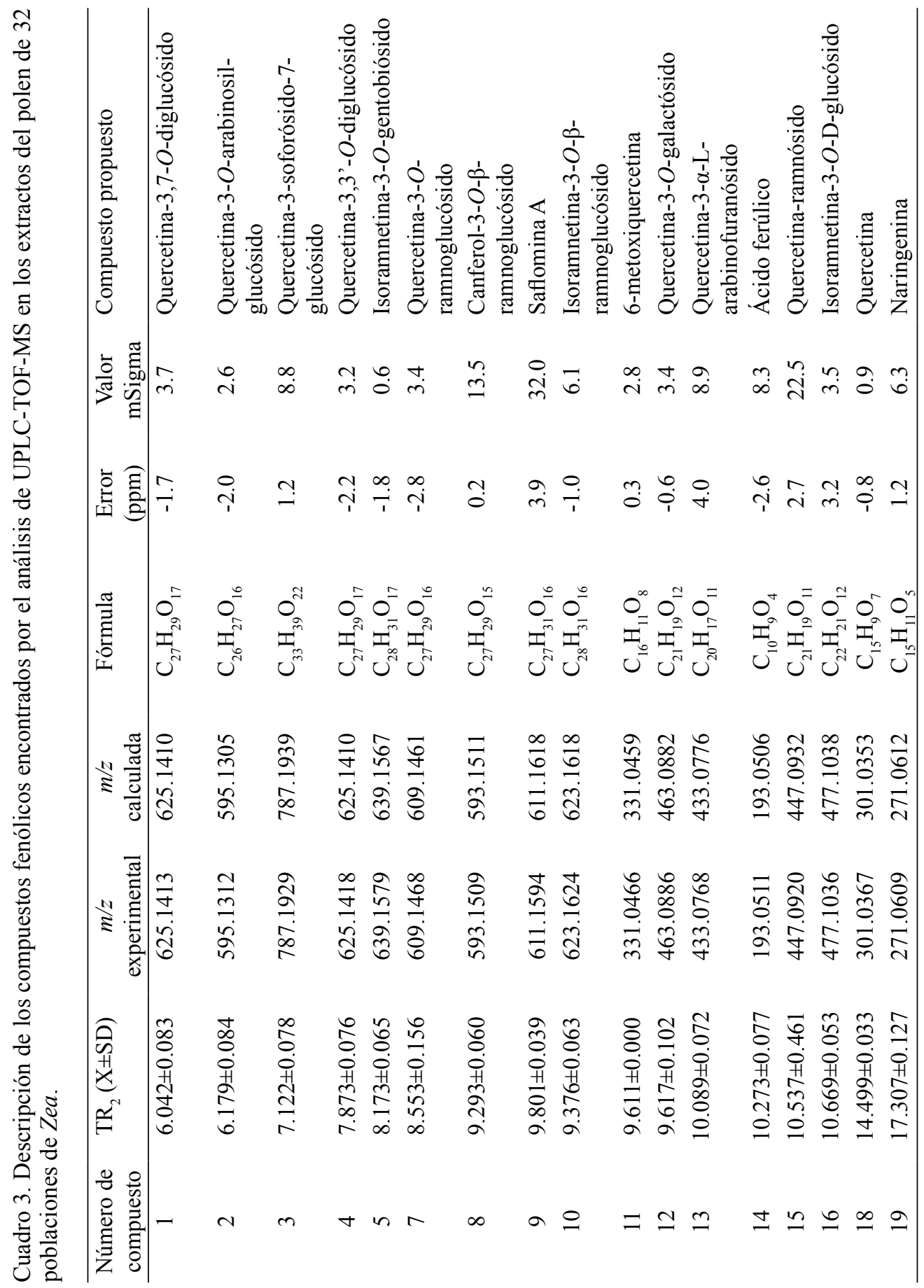




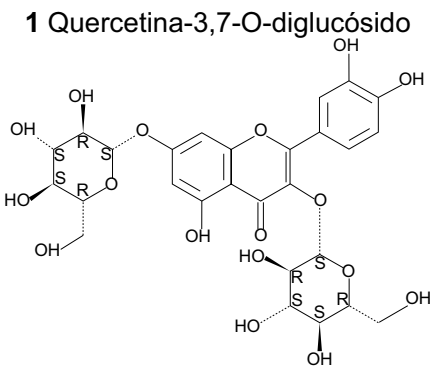

3 Quercetina-3-soforósido-7-glucósido

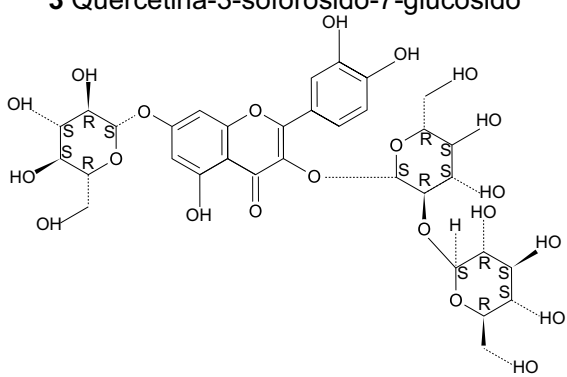

5 Isoramnetina-3-O-gentobiósido

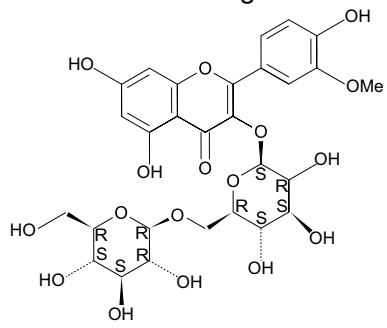

8 Canferol-3-O- $\beta$-ramnoglucósido<smiles>CCOc1c(-c2ccc(O)cc2)oc2cc(O)cc(O)c2c1=O</smiles>

10 Isoramnetina-3-O-ß-ramnoglucósido<smiles>CCOc1ccc(-c2oc3cc(O)cc(O)c3c(=O)c2OCCOCCOCCOCCO)c(O)c1</smiles>

2 Quercetina-3-O-arabinosilglucósido<smiles>COC1C(=O)c2c(O)cc(O)cc2OC1c1ccc(O)c(O)c1</smiles>

4 Quercetina-3-3'-O-diglucósido<smiles>OCCOCCO</smiles>

7 Quercetina-3-O-ramnoglucósido<smiles>COC1=C(c2ccc(O)c(O)c2)Oc2cc(O)cc(O)c2C1</smiles><smiles>O=C(/C=C/c1ccc(O)cc1)C1C(=O)C(C2CC(O)C(O)C(CO)O2)C(O)C2(OC(CO)C(O)C(O)C2O)C1O</smiles>

11 6-metoxiquercetina<smiles>O=c1c(O)c(O)c(O)cc2oc3ccc(O)c(O)c3c(=O)c12</smiles>

Fig. 2. Estructura de los compuestos 1 a $\mathbf{5}$ y 7 a $\mathbf{1 1}$ encontrados en el polen de Zea. 
12 Quercetina-3-O-galactósido<smiles>O=c1c(Oc2oc(CO)c(O)c2O)c(-c2ccc(O)c(O)c2)oc2cc(O)cc(O)c12</smiles>

15 Quercetina-ramnósido

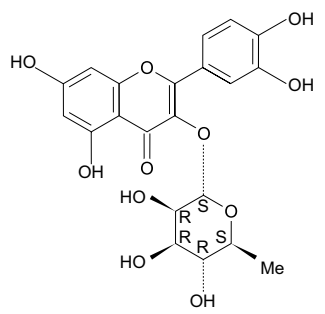

13 Quercetina-3- $\alpha$-L-arabinofuranósido

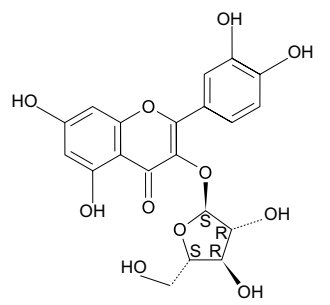

16 Isoramnetina-3-O-D-glucósido

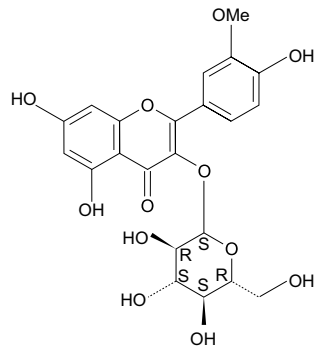

19 Naringenina

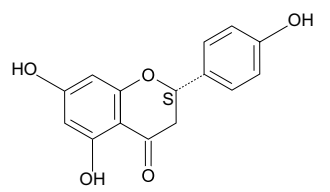

14 Ácido ferúlico

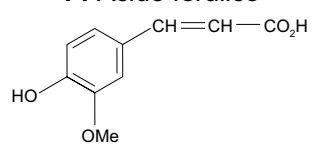

18 Quercetina

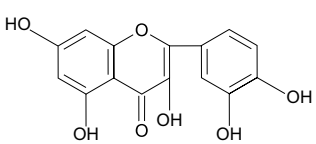

Fig. 3. Estructura de los compuestos 12 a 16, y 18 a 19 encontrados en el polen de Zea.

len de maíz, pero esos autores mencionaron que el canferol-3-O-glucósido (fórmula: $\mathrm{C}_{21} \mathrm{H}_{20} \mathrm{O}_{11}$, peso molecular: 448.38, $\lambda_{\text {max }}$ : 266, 297sh, 349) (Sakakibara et al., 2003; hoja de información técnica de Sigma Aldrich para ese compuesto) como el único derivado de canferol en el polen de esa especie, y de acuerdo con nuestros resultados, el único derivado de canferol encontrado fue el canferol-3-O- $\beta$-ramnoglucósido (8, fórmula: $\mathrm{C}_{27} \mathrm{H}_{29} \mathrm{O}_{15}, \mathrm{~m} / \mathrm{z}$ : 593.15, $\lambda_{\max }$ : 266, 300sh, 350, Cuadros 2 y 3, Fig. 2).

Recientemente, Chantarudee et al. (2012) reportaron la presencia de hidroquinona y 7-O-R-apigenina en las microsporas de maíz. En nuestro estudio, esos dos compuestos no fueron encontrados en el polen de ninguna de las especies ni subespecies de Zea analizadas. Nuestros resultados están de acuerdo con los de Ceska y Styles (1984), quienes resaltaron la ausencia de flavonas en el polen de Zea 
mays. Sin embargo, otras clases de fenoles, previamente no reportadas para tales microsporas, como ácidos fenólicos $(\mathbf{9}, \mathbf{2 2}$, y 23$)$ y dihidroflavonoides $(\mathbf{1 9}, \mathbf{2 0}$, y 21$)$ se detectaron en el presente estudio como compuestos menores en algunos de los parientes silvestres del maíz (Cuadros 2 y 3). La presencia de dihidroflavonoides fue previamente reportada en el polen de pinos (Strohl y Seikel, 1965).

Contrariamente a lo reportado por Ceska y Styles (1984), quienes mencionaron cuatro isoramnetinas glucósidos en el polen de maíz, y en contraste con Pollak et al. (1995), quienes no detectaron isoramnetina en el polen de ese mismo cereal, nosotros encontramos tres glicósidos de isoramnetina, la isoramnetina-3- $O$-gentobiósido (5) en todos los taxa de Zea, isoramnetina-3-O- $\beta$-ramnoglucósido (10) también en todos los taxa del género, e isoramnetina-3- $O$-D-glucósido (16) solamente en el polen de Z. perennis de Jalisco (694) y una población de Z. mays subsp. parviglumis (694).

Los flavonol-3-O-diglicósidos son los flavonoides más comúnmente acumulados en el polen, mientras que las agliconas se encuentran menos frecuentemente (Campos et al., 2002). Entre los pocos reportes que mencionan la presencia de flavonoides aglicona en el polen están el de Campos et al. (1997) en Eucalyptus globulus, y el de Campos et al. (2002) en Myrtaceae, subfamilia Leptospermoideae. Pollak et al. (1995) y previamente Larson y Lonergan (1972) registraron la acumulación de flavonoles agliconas además de flavonoles glicósidos en el polen de maíz. Sin embargo, con excepción de la quercetina aglicona (18), únicamente en el polen de Zea diploperennis de Nayarit (692), nosotros no encontramos flavonoles agliconas en los perfiles fenólicos del polen de Zea. Los flavonoides llevan a cabo diversas e importantes funciones en las plantas (Winkel-Shirley, 2001). Aunque no universalmente requeridos para la fertilidad del polen (Burbulis et al., 1996), en varias especies, incluyendo Zea mays, los flavonoles están involucrados en su germinación (Mo et al., 1992; Pollak et al., 1995). Esa función ha sido asociada a la quercetina, el canferol y a la miricetina (Ylstra et al., 1992; Vogt et al., 1995), pero particularmente en maíz se ha reportado la participación de la quercetina (Pollak et al., 1995). La predominancia de glicósidos de quercetina en el polen de todas las especies y subespecies de Zea analizadas en el presente estudio (Fig. 4) sugiere que, como en el maíz, la quercetina puede desempeñar una función similar en la germinación del polen y crecimiento del tubo polínico en las diferentes especies de teocintle.

Los perfiles fenólicos del polen de los diferentes taxa de Zea analizados fueron relativamente complejos (desde nueve compuestos en Zea mays susp. mays, a 14 en Zea mays subsp. mexicana raza Mesa Central de Michoacán, muestra 426, y de Durango, muestras 705 y 710), comparados con el número de compuestos en- 
contrados en el polen de otras especies, como Agave durangensis (Agavaceae), que varió entre seis y siete, todos los compuestos siendo derivados glicósidos de canferol (Almaraz-Abarca et al., 2009); cinco especies de Myrtaceae, que variaron de dos a cuatro flavonas agliconas (Campos et al., 2002); Bidens odorata (Compositae), que fue de tres, dos canferol glicósidos y un ácido cinámico (Almaraz-Abarca et al., 2004); y Salix atrocinerea, que fue de dos, el canferol-3- $O$-neo-hesperidósido y un derivado de ácido caféico (Campos, 1997). Sin embargo, también se han reportado perfiles fenólicos de polen más complejos que los encontrados para el polen de las especies y subespecies de Zea, como el de Stenocactus multicostatus subsp. zacatecasensis (Cactaceae), formado por 14 a 19 compuestos, y el de Echinocereus pectinatus (Cactaceae), compuesto por 12 a 17 (Almaraz-Abarca et al., 2007).

Pocos compuestos, todos ellos menores, se encontraron de manera exclusiva en alguno de los taxa de Zea analizados. La saflomina A (9) y el ácido ferúlico (14) fueron privativos del polen de Z. perennis de Jalisco (muestra 694). La quercetina-3$\alpha$-L-arabinofuranósido (13) estuvo presente solamente en $Z$. diploperennis (muestras 551 y 692). La quercetina aglicona (18) fue peculiar del polen de $Z$. diploperennis de Nayarit (muestra 692), y el compuesto 20, un dihidroflavonoide, se detectó únicamente en el de Z. mays subsp. parviglumis del sur de Guerrero (muestra 654). Aparte de esas diferencias, las microsporas de las especies y subespecies de Zea analizadas mostraron patrones muy similares de fenoles principales (Fig. 4). Los seis primordiales compuestos $(\mathbf{1}, \mathbf{3}, \mathbf{4}, \mathbf{5}, \mathbf{7}$ y 12) tuvieron la misma tendencia de acumulación en todas las muestras de polen de Zea analizadas (Fig. 4). El perfil formado por esos seis fenoles se podría considerar como un marcador químico para el género.

De acuerdo con Rice-Evans (1999), la estructura $O$-dihidroxi en el anillo B, el anillo $\mathrm{C}$ insaturado, y la estructura 5,7-dihidroxi en el anillo A de la quercetina confieren un alto potencial antioxidante, mientras que el anillo $\mathrm{B}$, con un solo grupo 4'-hidroxil del canferol y la isoramnetina les da a esos compuestos menores niveles de tal propiedad. La predominancia de glicósidos de quercetina sobre los de canferol e isoramnetina en el polen de los teocintles sugiere que tales microsporas representan una fuente importante de antioxidantes naturales, que pueden encontrarse formando parte de las mezclas polínicas de origen apícola, como ha sido corroborado por Almaraz-Abarca et al. (2004).

Variación interspecífica e intraspecífica

Los flavonoides son los principales marcadores quimiotaxonómicos (Markham, 1982; Campos et al., 2002; Almaraz-Abarca et al., 2004), pero los ácidos fenólicos también poseen cierto valor como indicadores químicos (Van Sume- 

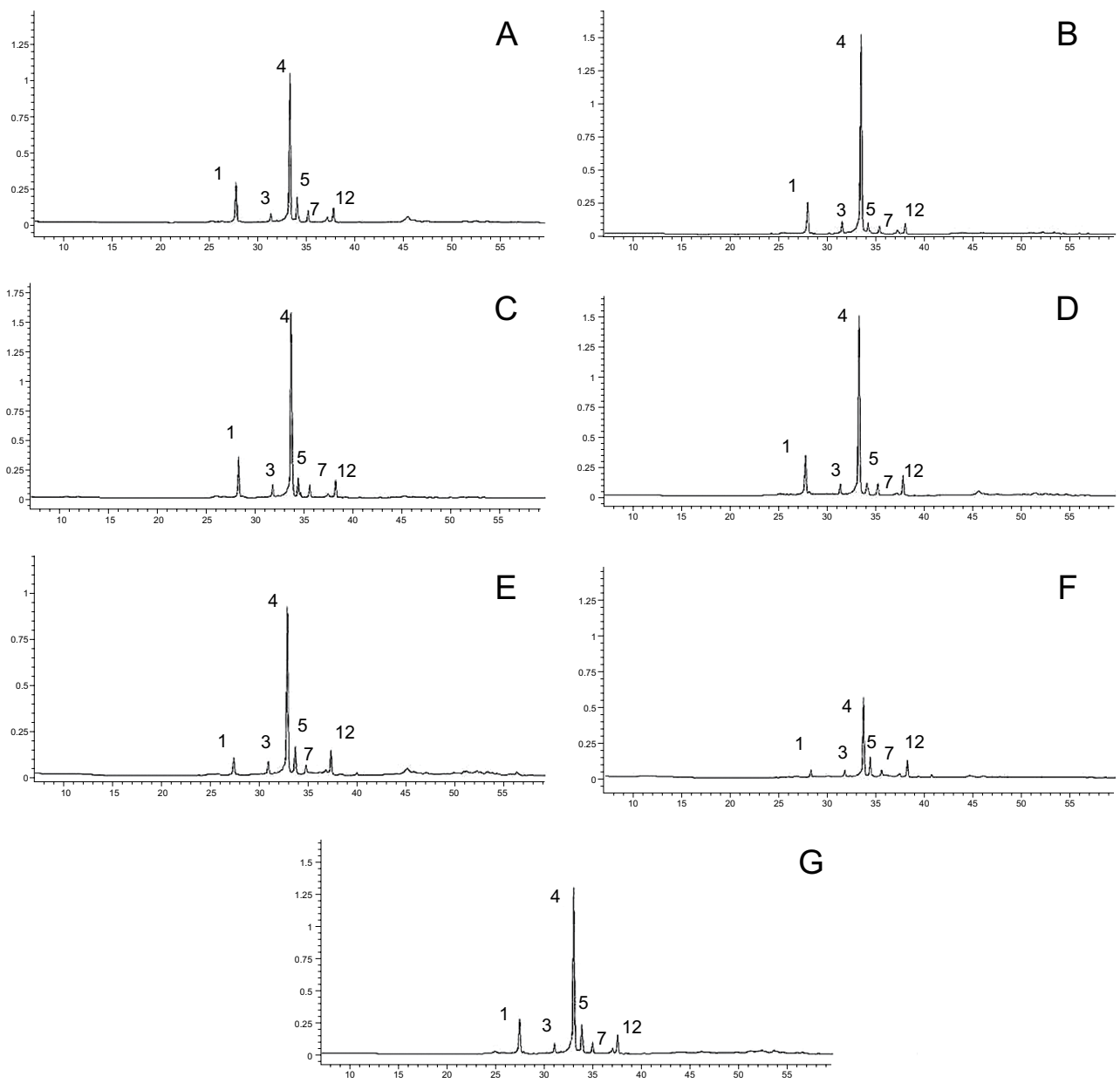

Fig. 4. Cromatogramas de HPLC de los polen de A: Zea mays subsp. parviglumis (muestra 201), B: Z. mays subsp. mexicana raza Mesa Central (muestra 426), C: Z. mays subsp. mexicana raza Nobogame (muestra 607), D: Z. mays subsp. mexicana raza Chalco (muestra 615), E: $Z$. diploperennis (muestra 551), F: Z. perennis (muestra 694), G: Z. luxurians (muestra G3). Los números de los picos corresponden al del compuesto como aparece en el Cuadro 2.

re, 1989), y pueden ser acumulados de manera ubicua a niveles importantes en los tejidos vegetales (Tamagnone et al., 1998). El polen de algunas especies de plantas es particularmente rico en ácidos fenólicos (Campos, 1997; Almaraz-Abarca et al., 2004, 2007), pero éstos pueden estar completamente ausentes en las microsporas de otras (Almaraz-Abarca et al., 2009). Con base en los perfiles completos de los fe- 
noles del polen, incluyendo los tres ácidos fenólicos encontrados, los resultados del presente estudio permitieron discernir algunas variaciones inter e intraespecíficas en Zea (Fig. 5).

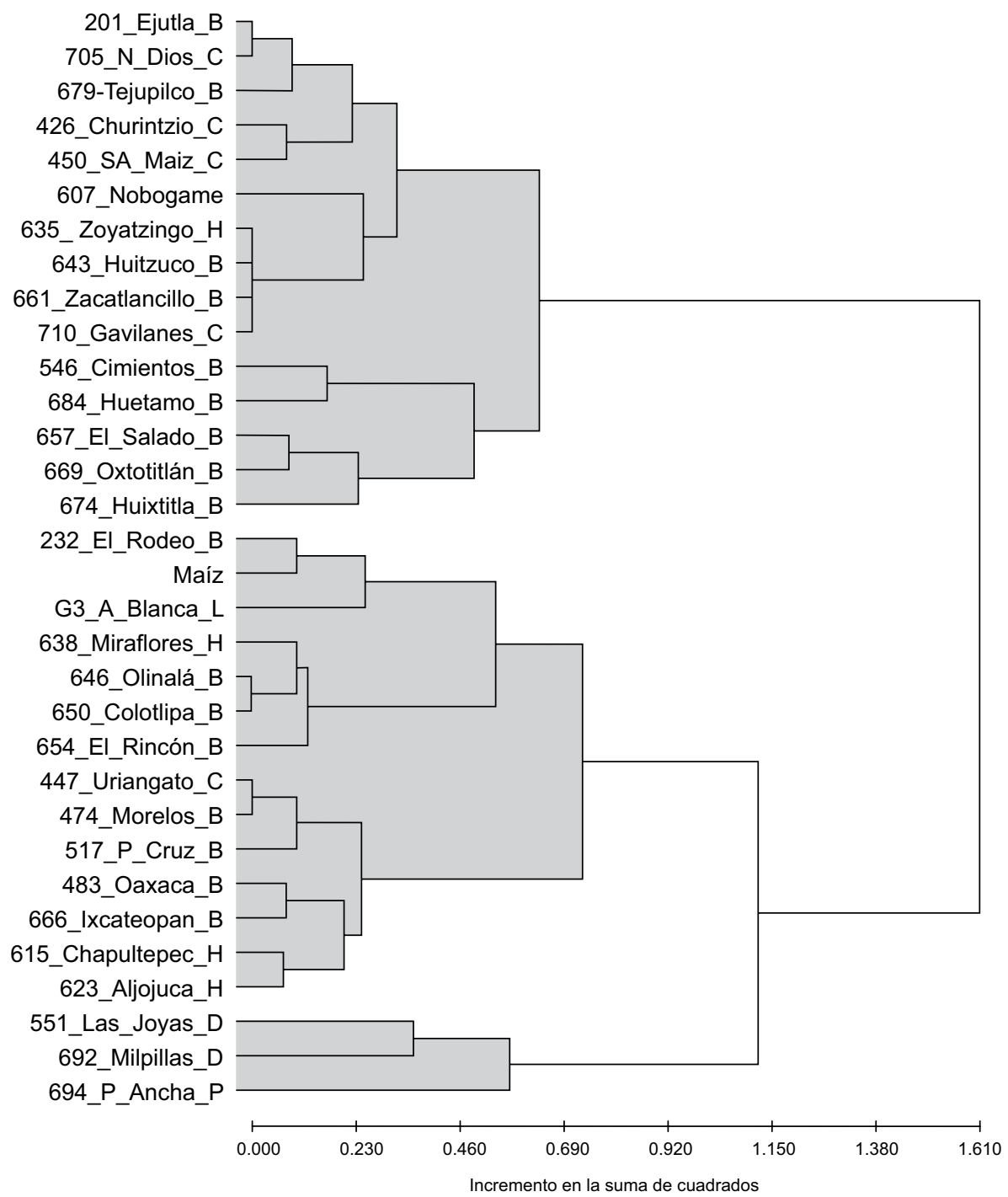

Fig. 5. Agrupamiento de los taxa de Zea enlistados en el Cuadro 1, con base en el método de Ward $(\mathrm{B}=$ Raza Balsas, $\mathrm{H}=$ Raza Chalco, $\mathrm{C}=$ Raza Mesa Central, $\mathrm{L}=Z$. luxurians, $\mathrm{D}=Z$. diploperennis, $\mathrm{P}=$ Z. perennis). 
El hecho de que todas las muestras del presente estudio fueron colectadas de plantas que crecieron bajo las mismas condiciones ambientales permite inferir que las diferencias encontradas en los perfiles fenólicos son el resultado de variaciones genéticas que dirigen un orden secuencial definido en la ruta de la biosíntesis. Esto es, de acuerdo con Heller y Forkmann (1994), propio y peculiar para cada especie de planta, y muchos de los pasos individuales de las modificaciones de los flavonoides están controlados por genes individuales (Forkmann, 1994).

El procedimiento de validación de árbol del método Clustan Graphics (Wishart, 2006), basado en 5000 pruebas aleatorias, encontró el número óptimo de grupos (clusters) y dividió a las muestras de teocintle en tres grupos. Este análisis, basado en una matriz binaria, reveló que los perfiles fenólicos del polen, difiriendo principalmente en compuestos menores, acomodan a Z perennis y $Z$. diploperennis en uno de los tres conjuntos (Fig. 5). Estos resultados apoyan parcialmente la actual división del género Zea aceptada por varios autores (Doebley y Iltis, 1980; Iltis y Doebley, 1980; Doebley, 1990; Iltis y Benz, 2000; Sánchez et al., 2011). Sin embargo, la separación de las secciones Luxuriantes y $Z e a$ propuesta por Doebly e Iltis (1980) no fue claramente encontrada, ya que $Z$. luxurians (G3) se situó fuera del grupo de Z. perennis y Z. diploperennis (Fig. 5), las otras dos especies de la sección Luxuriantes. El perfil fenólico del polen de Z. luxurians estuvo más cercanamente relacionado con los de Z. mays subsp. parviglumis y de maíz, que con cualquiera de las otras dos especies de Zea de la sección Luxuriantes. Una relación más cercana entre Z. luxurians y Z. mays subsp. parviglumis que entre $Z$. luxurians y $Z$. perennis o $Z$. diploperennis fue también encontrada por Tiffin y Gaut (2001), con base en la variabilidad de secuencia de cuatro loci nucleares. Zimmer et al. (1988), Purugganan y Wesler (1994), Buckler y Holtsford (1996), y Tiffin y Gaut (2001), basándose en varias clases de datos moleculares, opinaron que la sección Luxuriantes no es un grupo natural. Nuestros resultados representan evidencia química que apoya la propuesta de esos autores.

Tiffin y Gaut (2001) reportaron que Zea perennis es un autotetraploide derivado de Z. diploperennis. Nuestros datos químicos revelaron una relación cercana entre las dos muestras de teocintles perennes diploides (población 551 y población 692), y entre éstas y la especie perenne tetraploide (población 694), las tres formando un solo grupo (Fig. 5), lo cual da evidencia para apoyar el dictamen de Tiffin y Gaut (2001). Sin embargo, la baja variabilidad encontrada en los perfiles fenólicos del polen no permite inferir acerca del origen autotetraploide de $Z$. perennis a partir de Z. diploperennis. 
La cercana relación entre Zea mays subsp. mays con Z. mays subsp. parviglumis y Z. mays subsp. mexicana propuesta por algunos autores (Doebley et al., 1987) es sustentada por la similitud de sus patrones fenólicos polínicos. En dos de los tres grupos formados por el análisis de cluster (Fig. 5), poblaciones de la subsp. mexicana y la subsp. parviglumis se mezclan unas con otras, y algunas de las dos subespecies tienen perfiles fenólicos del polen muy similares, como la 474 de la subsp. parviglumis y la 447 de la subsp. mexicana; la 201 de la subsp. parviglumis y la 705 de la subsp. mexicana; y las 643 y 661 de la subsp. parviglumis y las 710 y 635 de la subsp. mexicana (Fig. 5). De manera similar a los resultados basados en el análisis de restricción de cpDNA (Doebley et al., 1987), los perfiles fenólicos del polen no discriminan entre $Z$. mays subsp. mexicana y Z. mays subsp. parviglumis (Fig. 5), diferenciación que sí ha podido realizarse usando datos de isozimas, morfológicos (Doebley, 1983; Goodman y Stuber, 1983; Doebley et al., 1984), y moleculares de genoma nuclear (Fukunga et al., 2005). Nuestros resultados sugieren que en el género Zea la tasa de evolución de los patrones fenólicos del polen ha estado desacoplada de la evolución de caracteres moleculares nucleares, bioquímicos y morfológicos. Un desacoplamiento similar de la evolución de caracteres ha sido reportada para el género Plagiomnium de musgos (Harris, 2009). Esa incongruencia entre diferentes clases de atributos ha sido explicada como una evolución asincrónica de marcadores (Hörandl, 2010).

La hibridación y la introgresión son eventos frecuentemente encontrados en muchas poblaciones naturales de plantas (Harborne y Turner, 1984), y su importancia en promover cambios evolutivos es tal que varios autores han estimado que alrededor de $70 \%$ de todas las especies de angiospermas se han originado por hibridación (Arnold, 1994; Whitham et al., 1999). La hibridación origina variación cualitativa y cuantitativa en los patrones de metabolitos secundarios (Orians et al., 2000), generando más variabilidad en las generaciones de híbridos posteriores a F1 (Rieseberg y Ellstrand, 1993). La baja diversidad encontrada en los perfiles fenólicos del polen de las especies y subespecies analizadas de Zea apoya lo reportado por Ross-Ibarra et al. (2009) acerca de que la hibridación y la introgresión, que de haber ocurrido entre varios taxa de Zea, no han sido eventos comunes. Los patrones actuales de distribución geográfica, en los que muchas poblaciones no se encuentran en forma simpátrica (Sánchez et al., 2011), sustenta también la afirmación de RossIbarra et al. (2009).

La baja variabilidad encontrada en el presente trabajo en los patrones fenólicos del polen de Zea sugiere que esos perfiles han estado muy conservados durante el surgimiento de las diferentes especies del género, lo cual ocurrió casi de manera contemporánea hace 100,000 a 300,000 años (Gaut y Clegg, 1993; Ross-Ibarra et al., 
2009), lo que podría estar asociado al importante papel que los flavonoides llevan a cabo en el funcionamiento normal del polen (Coe et al., 1981), como ha sido corroborado en maíz (Pollak et al., 1995).

Nuestros resultados se suman a la propuesta de algunos autores (Doebley et al., 1984; Doebley et al., 1987) de considerar al maíz y algunos teocintles como grupos conespecíficos, los cuales comparten procesos celulares esenciales del desarrollo (Dermastia et al., 2009) pues también comparten procesos cruciales de la síntesis y acumulación de fenoles en las estructuras reproductivas masculinas, como lo revela la semejanza encontrada de los perfiles fenólicos.

El perfil fenólico del polen de maíz y el de algunas poblaciones de Zea mays subsp. parviglumis, particularmente la 232 de Jalisco, son muy similares (Fig. 5). Esa semejanza brinda evidencia química que apoya la propuesta de Doebley et al. (1987) de que esa subespecie fue la progenitora del maíz.

\section{CONCLUSIONES}

El polen de Zea mays subsp. mexicana, Z. mays subsp. parviglumis, Z. mays subsp. mays, Z.diploperennis, Z. perennis, y Z. luxurians tienen patrones similares de acumulación de compuestos fenólicos, principalmente derivados glicósidos de quercetina, lo que lo hace una fuente importante de flavonoides antioxidantes. Los perfiles fenólicos de las especies y subespecies de Zea son muy semejantes, lo que es una evidencia química que apoya los hallazgos que han hecho diversos autores de que el maíz y algunos teocintles son grupos conespecíficos. La separación, con base en los perfiles fenólicos del polen, de Z. luxurians del grupo de $Z$. perennis y $Z$. diploperennis sustentan la propuesta de que la sección Luxuriantes no es un grupo natural.

\section{AGRADECIMIENTOS}

Los autores agradecen a la Comisión de Operación y Fomento a las Actividades Académicas (COFAA) por los estímulos a la investigación, al Instituto Politécnico Nacional por el financiamiento de la investigación a través del proyecto SIP 20110499, y a Patricia García Salas y Celia Rodríguez del Centro de Investigación y Desarrollo del Alimento Funcional de Granada, España por su ayuda en los análisis de UPLC. 


\section{LITERATURA CITADA}

Almaraz-Abarca, N., M. G. Campos, J. A. Ávila-Reyes, N. Naranjo-Jiménez, J. HerreraCorral y L. S. González-Valdez. 2004. Variability of antioxidant activity among honeybee-collected pollen of different botanical origin. Interciencia 29: 574-578.

Almaraz-Abarca, N., M. S. González-Elizondo, J. A. Tena-Flores, J. A. Ávila-Reyes, J. Herrera-Corral y N. Naranjo-Jiménez. 2006. Foliar flavonoids distinguish Pinus leiophylla and Pinus chihuahuana (Coniferales: Pinaceae). Proc. Biol. Soc. Wash. 119: 426-436.

Almaraz-Abarca, N., M. G. Campos, A. Delgado-Alvarado, J. A. Ávila-Reyes, N. NaranjoJiménez, J. Herrera-Corral, A. F. Tomatas, A. J. Almeida y A. Vieira. 2007. Fenoles del polen de Stenocactus, Echinocereus y Mammillaria (Cactaceae). Polibotánica 23: 37-55.

Almaraz-Abarca, N., M. G. Campos, E. A. Delgado-Alvarado, J. A. Ávila-Reyes, J. HerreraCorral, L. S. González-Valdez, N. Naranjo-Jiménez, C. Frigerio, A. F. Tomatas, A. J. Almeida, A. Vieira y J. N. Uribe-Soto. 2008. Pollen flavonoid/phenolic acid composition of four species of Cactaceae and its taxonomic significance. Am. J. Agr. Biol. Sci. 3: 534-543.

Almaraz-Abarca, N., E. A. Delgado-Alvarado, V. Hernández-Vargas, M. Ortega-Chávez, G. Orea-Lara, A. Cifuentes-Díaz de León, J. A. Ávila-Reyes y R. Muñiz-Martínez. 2009. Profiling of phenolic compounds of somatic and reproductive tissues of Agave durangensis Gentry (Agavaceae). Am. J. Appl. Sci. 6: 1076-1085.

Arnold, M. L. 1994. Natural hybridization and Louisiana irises. BioScience 44: 141-147.

Buckler, E. S. y T. P. Holtsford. 1996. Zea systematics: ribosomal ITS evidence. Mol. Biol. Evol. 13: 612-622.

Burbullis, I. E., M. Iacobucci y B. E. Shirley. 1996. A null mutation in the first enzyme of flavonoid biosynthesis does not affect male fertility in Arabidopsis. Plant Cell 8: 1013-1025.

Campos, R. M. G. 1997. Caracterizaçao do polen apícola pelo seu perfil em compostos fenólicos e pesquisa de algumas actividades biológicas. Dissertação de candidatura ao grado de Doutor. Universidade de Coimbra. Coimbra, Portugal. 318 pp.

Campos, M. G. y K. M. Markham. 2007. Structure information from HPLC and online measured absorption spectra-flavone, flavonols and phenolic acids. Coimbra University Press. Coimbra, Portugal. 118 pp.

Campos, M., K. R. Markham, K. A. Mitchell y A. Proenca da Cunha. 1997. An approach to the characterization of bee pollens via their flavonoid/phenolic profiles. Phytochem. Anal. 8: 181-185.

Campos, M. G., R. F. Webby y K. R. Markham. 2002. The unique occurrence of the flavone aglycone tricin in Myrtaceae pollen. Z. Naturforsch C 57c: 944-946.

Casati, P. y V. Walbot. 2003. Gene expression profiling in response to ultraviolet radiation in maize genotypes with varying flavonoid content. Plant Physiol. 132: 1739-1754.

Ceska, O. y E. D. Styles. 1984. Flavonoids from Zea mays pollen. Phytochemistry 23: 18221823. 
Chantarudee, A., P. Phuwapraisirisan, K. Kimura, M. Okuyama, H. Mori, A. Kimura y C. Chanchao. 2012. Chemical constituents and free radical scavenging activity of corn pollen collected from Apis mellifera hives compared to floral corn pollen at Nam, Thailand. BMC Complement. Altern. Med. 12: 45.

Coe, E. H., S. M. McCormick y S. A. Modena. 1981. White pollen in maize. J. Hered. 72: 318-320.

Cohen, J. I. y W. C. Galinat. 1984. Potential use of alien germoplasm for maize improvement. Crop Sci. 24: 1011-1015.

Dahia, M., L. Siracusa, H. Laouer y G. Ruberto. 2009. Constituents of the polar extracts from Algerian Pituranthos scoparius. Nat. Prod. Commun. 4: 1691-1692.

Dermastia, M., A. Kladnik, J. D. Koce y P. S. Chourey. 2009. A cellular study of Teosinte Zea mays subsp. parviglumis (Poaceae) caryopsis development showing several processes conserved in maize. Am. J. Bot. 96: 1798-1807.

Doebley, J. 1990. Molecular systematics of Zea (Gramineae). Maydica 35: 143-150.

Doebley, J. 1983. The maize and teosinte male inflorescence: a numerical taxonomic study. Ann. Mo. Bot. Gard. 70: 32-70.

Doebley, J., M. M. Goodman y C. W. Stuber. 1984. Isoenzymatic variation in Zea (Gramineae). Syst. Bot. 9: 203-218.

Doebley, J. y H. H. Iltis. 1980. Taxonomy of Zea (Gramineae) I. A subgeneric classification with key to taxa. Am. J. Bot. 67: 982-993.

Doebley, J., W. Renfroe y A. Blanton. 1987. Restriction site variation in the Zea chloroplast genome. Genetics 117: 139-147.

Ferracane, R., G. Graziani, M. Gallo, V. Fogliano y A. Ritieni. 2010. Metabolic profile of the bioactive compounds of burdock (Arctium lappa) seeds, roots and leaves. J. Pharm. Biomed. Anal. 51: 399-404.

Fiasson, J., L. K. Gluchoff-Fiasson y G. Dahlgren. 1997. Flavonoid patterns in European Ranunculus L. subgenus Batrachium (Ranunculaceae). Biochem. Syst. Ecol. 25: 327333.

Forkmann, G., 1994. Genetics of flavonoids. In: Harborne, J. B. (ed.). The Flavonoids. Advances in Research since 1986. Chapman \& Hall. London, UK. pp. 537-564.

Fukunga, K., J. Hill, Y. Vigouroux, Y. Matsuoka, G. J. Sánchez, K. Liu, E. S. Buckler y J. Doebley. 2005. Genetic diversity and population structure of teosinte. Genetics 169: 2241-2254.

Gardana, C., M. Scaglianti, P. Pietta y P. Simonetti. 2007. Analysis of the polyphenolic fraction of propolis from different sources by liquid chromatogrphy-tandem mass spectrometry. J. Pharm. Biomed. Anal. 45: 390-399.

Gaut, B. S. y M. T. Clegg. 1993. Molecular evolution of the Adh1 locus in the genus Zea. Proc. Nat. Acad. Sci. USA 90: 5095-5099.

Goodman, M. M. y C. W. Stuber. 1983. Races of maize VI. Isozyme variation among races of maize in Bolivia. Maydica 28: 169-187.

Gross, J. H. 2010. Mass spectrometry. A texbook. 2nd ed. Springer. Berlin, Germany. 753 pp.

Harborne, J. B. y B. L. Turner. 1984. Plant chemosystematics. Academic Press. London, UK. 562 pp. 
Harris, E. S. J. 2009. Phylogenetic and environmental lability of flavonoids in a medicinal moss. Biochem. Syst. Ecol. 37: 180-192.

Heller, W. y G. Forkmann. 1994. Biosynthesis of flavonoids. In: Harborne, J. B. (ed.). The flavonoids. Advances in research since 1986. Chapman \& Hall. London, UK. pp. 499-535.

Hiraoka, A., K. Yoshitama, T. Hine, T. Tayeoka y T. N. Tateoka. 1987. Isotachophoresis of flavonoids. Chem. Pharm. Bull. 35: 4317-4320.

Hörandl, E. 2010. Beyond cladistics: extending evolutionary classification into deeper time levels. Taxon 59: 345-350.

Iltis, H. H. y B. F. Benz. 2000. Zea nicaraguensis (Poaceae), a new teosinte from Pacific Coastal Nicaragua. Novon 10: 382-390.

Iltis, H. H. y J. F. Doebley. 1980. Taxonomy of Zea (Graminae) II. Subspecific categories in the Zea mays complex and a generic synopsis. Am. J. Bot. 67: 994-1004.

Iswaldi, I., D. Arráez-Román, I. Rodríguez-Medina, J. Beltrán-Debón, J. Joven, A. SeguraCarretero y A. Fernández-Gutiérrez. 2011. Identification of phenolic compounds in aqueous and ethanolic rooibos extracts (Aspalathus linearis) by HPLC-ESI-MS (TOF/IT). Anal. Bioanal. Chem. 400: 3643-3654.

Larson R. L. y C. M. Lonergan. 1972. Glucosyltransferase activity in a water extract of maize pollen. Planta 103: 361-364.

Lee, E. A., P. F. Byrne, M. D. McMullen, M. E. Snook, B. R. Wiseman, N. W. Widstrom y E. H. Coe. 1998. Genetic mechanisms underlying apimaysin and maysin synthesis and cornantibiosis in maize (Zea mays L.). Genetics 149: 1997-2006.

Mabry, T. J., K. M. Markham y M. B. Thomas. 1970. The systematic identification of flavonoids. Springer-Verlag. New York, USA. 354 pp.

Markham, K. R. 1982. Techniques of flavonoid identification. Academic Press. London, UK. 113 pp.

Markham, K. R. y M. Campos. 1996. 7- and 8-O-methylherbacetin-3-O-sophorosides from bee pollens and some structure/activity observations. Phytochemistry 43: 763-767.

Mo, Y., C. Nagel y L. P. Taylor. 1992. Biochemical complementation of chalcone synthase mutants defines a role for flavonols in functional pollen. Proc. Nat. Acad. Sci. USA 89: 7213-7217.

Morikawa, T., L. Wang, S. Nakamura, K. Ninomiya, E. Yokoyama, H. Matsuda, O. Muraoka, L. Wu y M. Yoshikawa. 2009. Medicinal flowers. XXVII. New flavanone and chalcone glycosides, arenariumosides I, II, and IV, and tumor necrosis factor- $\alpha$ inhibitors from everlasting, flowers of Helichrysum arenarium. Chem. Pharm. Bull. 57: 361-367.

Nault, L. R. y W. R. Findley. 1981. Zea diploperennis: a primitive relative offers new traits to improve corn. Ohio Rep. Res. Dev. 66: 90-92.

Orians, C. M., M. Griffiths, B. M. Roche y R. S. Fritz. 2000. Phenolic glycosides and condensed tannins in Salix sericea, S. eriocephala and their F1 hybrids: not all hybrids are created equal. Biochem. Syst. Ecol. 28: 619-632.

Pollak, P. E., K. Hansen, J. D. Astwood y L. P. Taylor. 1995. Conditional male fertility in maize. Sex Plant Reprod. 8: 231-241.

Purugganan, M. D. y S. R. Wessler. 1994. Molecular evolution of megallan, a maize Ty3/ gypsy like retrotransposon. Proc. Nat. Acad. Sci. USA 91: 11674-11678. 
Rice-Evans, C. 1999. Screening of phenolics and flavonoids for antioxidant activity. In: Packer, L., M. Hiramatsu y T. Yoshikawa (eds.). Antioxidant food supplements in human health. Academic Press. California, USA. pp. 239-253.

Rieseberg, L. H. y N. C. Ellstrand. 1993. What can molecular and morphological markers tell us about plant hybridization? Crit. Rev. Plant Sci. 12: 213-241.

Rochfort, S. J., M. Imsic, R. Jones, V. C. Trenerry y B. Tomkins. 2006. Characterization of flavonol conjugates in immature leaves of pak choi [Brassica rapa L. ssp. chinensis L. (Hanelt)] by HPLC-DAD and LC-MS/MS. J. Agric. Food Chem. 54: 4855-4860.

Ross-Ibarra, J., M. Tenaillon y B. S. Gaut. 2009. Historical divergence and gene flow in the genus Zea. Genetics 181: 1399-1413.

Sakakibara, H., Y. Honda, S. Nakagawa, H. Ashida y K. Kanasawa. 2003. Simultaneous determination of all phenolics in vegetables, fruits, and teas. J. Agric. Food Chem. 51: 571-581.

Sánchez-González, J. J., Y. T. A. Kato, S. M. Aguilar, C. J. M. Hernández, R. A. López y C. J. A. Ruiz. 1998. Distribución y caracterización del teocintle. INIFAP. Guadalajara, México. 149 pp.

Sánchez, J. J., M. M. Goodman y C. W. Stuber. 2000. Isozymatic and morphological diversity in the races of maize of Mexico. Econ. Bot. 54: 43-59.

Sánchez G., J. J., L. De la Cruz L., V. A. Vidal M., J. Ron P., S. Taba, F. Santacruz-Ruvalcaba, S. Sood, J. B. Holland, J. A. Ruíz C., S. Carvajal, F. Aragón C., V. H. Chávez T., M. M. Morales R. y R. Barba-González. 2011. Three new teosintes (Zea spp., Poaceae) from Mexico. Am. J. Bot. 98: 1537-1548.

Schieber, A., N. Berardini y R. Carle. 2003. Identification of flavonol and xanthone glycosides from mango (Mangifera indica L. Cv. "Tommy Atkins") peels by high-performance liquid chromatography-electrospray ionization mass spectrometry. J. Agric. Food Chem. 51: 5006-5011.

Strohl, M. J. y M. K. Seikel. 1965. Polyphenols of pine pollen: a survey. Phytochemistry 4 : 383-399.

Tamagnone, L., A. Merida, N. Stacy, K. Plaskitt, A. Parr, C. F. Chang, D. Lynn, J. Maxwell, K. Roberts y C. Martin. 1998. Inhibition of phenolic acid metabolism results in precocious cell death and altered cell morphology in leaves of transgenic tobacco plants. Plant Cell 10: 1801-1816.

Tao, W., N. Yang, J. Duan, D. Wu, J. Gou, Y. Tang, D. Qian y Z. Zhu. 2011. Simultaneous determination of eleven major flavonoids in the pollen of Typha angustifolia by HPLC-PDA-MS. Phytochem. Anal. 22: 455-461.

Tiffin, P. y B. S. Gaut. 2001. Sequence diversity in the tetraploid Zea perennis and the closely related diploid $Z$. diploperennis: insights from four nuclear loci. Genetics 158: 401-412.

Vallejo, F., F. A. Tomás-Barberán y F. Ferreres. 2004. Characterization of flavonols in broccoli (Brassica oleracea L. var. italica) by liquid chromatography-UV diodearray detection-electrospray ionization mass spectrometry. J. Chromatogr. A 1054: 181-193.

Van Sumere, C. F. 1989. Phenols and phenolic acids. In: Harborne, J. B. (ed.). Methods in plant biochemistry. Vol 1. Academic Press. London, UK. pp. 29-73. 
Wiermann, R. y K. Vieth. 1983. Outer pollen wall, an important accumulation site for flavonoids. Protoplasma 118: 230-233.

Vogt, T., E. Wollenweber y L. P. Taylor. 1995. The structural requirements of flavonols that induce pollen germination of conditionally male fertility petunia. Phytochemistry 38: 589-592.

Whitham, T. G., G. D. Martinsen, K. D. Floate, H. S. Dungey, B. M. Potts y P. Keim. 1999. Plant hybrid zones affect biodiversity: tools for a genetic-based understanding of community structure. Ecology 80: 416-428.

Wilkes, G. 2004. Corn, strange and marvelous: but is a definitive origin known? In: Smith, C. W. (ed.). Corn: origin, history, technology, and production. John Wiley \& Sons. New York, USA. pp. 3-63.

Winkel-Shirley, B. 2001. It takes a garden. How work on diverse plant species has contributed to an understanding of flavonoid metabolism. Plant Physiol. 127: 1399-1404.

Wishart, D. 2006. Clustan graphics primer: A guide to cluster analysis. Clustan Limited. Edinburgh, Scotland. 64 pp.

Ylstra, B., T. Alisher, M. R. M. Benito, E. Stöger, A. J. van Tunen, O. Vicente, J. N. M. Mol y E. Heberle-Bors. 1992. Flavonols stimulate development, germination, and tube growth of tobacco pollen. Plant Physiol. 100: 902-907.

Zhang, X., R. Boytner, J. L. Cabrera y L. Richard. 2007. Identification of yellow dye types in pre-columbian Andean textiles. Anal. Chem 79: 1575-1582.

Zhang, Q. y H. Cui. 2005. Simultaneous determination of quercetin, kaempferol, and isorrhamnetin in phytopharmaceuticals of Hippophae rhamnoides L. by highperformance liquid chromatography with chemiluminescence detection. J. Sep. Sci. 28: 1171-1178.

Zimmer, E. A. y E. R. Jupe, V. Walbot. 1988. Ribosomal gene structure, variation and inheritance in maize and its ancestors. Genetics 120: 1125-1136.

Recibido en enero de 2013.

Aceptado en junio de 2013. 